\title{
Participation of Mothers Who Work in Religious Activities Towards Child Behavior
}

\author{
Anti Isnaningsih ${ }^{1}$, Arif Rochman ${ }^{2}$ \\ Pendidikan Anak Usia Dini, Pascasarjana, Universitas Negeri Yogyakarta
}

\begin{abstract}
One of the provisions of parents to stimulate aspects of moral religious behavior in early childhood at home is by attending religious activities held in schools and places of worship. The study involved 26 children aged 4-6 years from working mothers. With a quantitative descriptive research approach the type of correlation is from mothers who have careers and participate in religious activities or not. This study looked at whether there were differences in moral religious behavior of children from both parents' backgrounds. The results showed that there were differences in the moral behavior of children's religion seen from the results of the Mann Whitney $t$ test obtained by the results of sig. equal to 0,000 or < probability value that is 0.05. The effect of caregiving is proven on the behavior of children of mothers who attend religious activities that are more controlled than children of mothers who do not attend religious activities. Children tend not to be temperament, able to resist emotions, help each other, easily forgive and get used to pray before and after doing activities. This finding proves that nurturing the role of mother in the home environment is very influential despite being busy with her work.
\end{abstract}

Keywords: Working mother's participation; Religious activity; Children's moral behavior

\begin{abstract}
Abstrak
Salah satu bekal orangtua untuk memberikan stimulasi aspek perilaku agama moral anak usia dini di rumah adalah dengan mengikuti kegiatan keagamaan yang diselenggarakan di sekolah maupun tempat ibadah. Penelitian melibatkan 26 anak usia 4-6 tahun dari ibu yang bekerja. Dengan pendekatan penelitian deskriptif kuantitatif jenis komparasi dari ibu yang memiliki karir dan mengikuti kegiatan keagamaan maupun tidak. Penelitian ini melihat apakah terdapat perbedaan perilaku agama moral anak dari kedua latar belakang orangtua tersebut. Hasil penelitian menunjukan terdapat perbedaan perilaku agama moral anak terlihat dari hasil uji $\mathrm{t}$ Mann Whitney diperoleh hasil sig. sebesar 0.000 atau < nilai probailitas yakni 0.05 sehingga Ha diterima. Pengaruh pengasuhan terbukti pada perilaku anak dari ibu yang mengikuti kegiatan keagamaan yakni lebih terkendali dari pada anak dari ibu yang tidak mengikuti kegiatan keagamaan. Anak cenderung tidak tempramen, mampu menahan emosi, saling membantu, mudah memaafkan serta terbiasa berdoa sebelum dan sesudah melakukan kegiatan. Temuan ini membuktikan bahwa pengasuhan peran ibu di lingkungan rumah sangat berpengaruh walaupun sibuk dengan pekerjaanya.
\end{abstract}

Kata Kunci : Partisipasi Ibu yang bekerja; Kegiatan Keagamaan; Perilaku NAM anak

@ Jurnal Obsesi Prodi PG-PAUD FIP UPTT 2019

$\square$ Corresponding author :

Address : Jl. Colombo No.1, Karang Malang

ISSN 2356-1327 (Media Cetak)

Email : antiisnaningsih@gmail.com

ISSN 2549-8959 (Media Online)

Phone : +62 856-4770-77 


\section{PENDAHULUAN}

Anak usia dini adalah anak yang berada pada rentan usia 0-6 tahun. Pada masa ini disebut sebagai masa golden age dimana sel syaraf neuron dalam otak sedang berkembang pesat dan sangat peka terhadap rangsangan atau stimulasi yang diterima (Suyanto, 2005). Untuk itu hendaknya stimulasi yang diberikan harus tepat agar semua aspek perkembangan anak dapat berkembang dengan optimal (Setiawati \& Yogyakarta, 2006). Salah satu aspek perkembangan anak adalah nilai agama moral (NAM), aspek ini mempunyai peran penting terhadap kehidupan anak karena menyangkut pembentukan sikap perilaku, oleh karenanya nilai-nilai keagamaan dapat ditempuh melalui pendidikan, baik itu pendidikan di lingkungan sekolah, lingkungan keluarga, maupun lingkungan masyarakat.

$$
\text { Perilaku nilai agama moral bisa }
$$
dibentuk dan distimulasi melalui pendidikan keagamaan yang berkaitan dengan perilaku pembiasaan untuk meningkatkan potensi spiritual yang telah dimiliki (Khadijah, 2016). Selain untuk anak, pendidikan agama juga dapat dijadikan sebagai landasan oleh orang tua dalam proses pengasuhan yang akan memberikan dampak terhadap perilaku anak usia dini di masa mendatang untuk kehidupan sehari-hari karena perilaku anak usia dini terbentuk dari lingkungan sekitar. Melihat pentingnya masa depan anak yang merupakan generasi penerus keluarga serta penerus bangsa, sehingga perlu mendapatkan stimulasi tepat dan optimal untuk mengembangkan potensi dalam diri.

Keluarga merupakan tempat untuk mengembangkan potensi anak ke arah pengembangan kepribadian diri yang positif dan baik karena pendidikan di dalam keluarga merupakan usaha oleh ayah maupun ibu sebagai orang yang diberi tanggung jawab untuk memberikan nilainilai, akhlak, keteladanan, dan kefitrahan (Langgulung, 1986). Selain itu keluarga juga sebagai tempat pendidikan budi pekerti, sosial, kewarganegaraan, serta pembentukan kebiasaan dan pendidikan intelektual pada anak yang nantinya akan terbentuk menjadi suatu pola perilaku (Jailani, 2014)

Intensitas peluang waktu stimulasi anak usia dini cendrung lebih banyak bergaul dengan orang tua atau keluarga di rumah dari pada di sekolah. Sehingga perkembangan anak secara langsung dipengaruhi oleh orang-orang sekitar seperti orangtua dan saudara kandung melalui interaksi keluarga. Dalam hasil penelitian (Isticharoh, 2007) tantang pembentukan perilaku akhlak, bahwa salah satu faktor yang mendukung pembentukan perilaku akhlak pada anakmasa prasekolah adalah lingkungan dimana anak tersebut tinggal.

Lingkungan secara tidak langsung akan membentuk moral dan perilaku individu. Perilaku moral merupakan bagian dari ajaran agama yaitu akhlak, begitu juga sebaliknya akhlak juga bagian dari perilaku moral. Perilaku moral dan ahlak merupakan bagian dari lingkup agama yang tidak dapat dipisahkan, perilaku moral timbul berdasarkan lingkungan masyarakat sedangkan akhlak berdasarkan agama. Akhlak merupakan sifat yang melekat dalam jiwa seseorang yang menjadikan manusia dengan mudah bertindak tanpa pertimbangan(Bakry, 1993). Sedangkan perilaku moral merupakan perilaku yang sesuai dengan kode moral suatu kelompok sosial seperti peraturan yang telah menjadi kebiasaan bagi anggota suatu budaya (Hurlock, 1978).

Perilaku moral dan ahlak mulai terbentuk dari lingkup yang paling kecil yakni lingkungan keluarga, dalam penelitian (Petts, 2012) disampaikan bahwa terdapat perbedaan perilaku anak usia dini yang mempunyai faktor latar belakang kondisi lingkungan keluarga yang berbeda, yakni orangtua utuh maupun orangtua tunggal baik yang disebabkan karena perceraian maupun diluar pernikahan. Peran pengasuhan orangtua tunggal yang diimbangi dengan keagamaan dapat memberikan pengaruh positif terhadap perkembangan perilaku anak dalam kehidupanya seperti mudah memaafkan teman, terkendalinya rasa dendam, menekankan sikap egois sesama teman dan 
mudah membantu dengan teman baik teman sebaya maupun dengan teman usia yang lebih muda (Mahoney, 2010). Dalam penelitian (Zhai, Jiexia Elisa, Ellison G. Christopher, dan Glenn, 2007) juga disampaikan bahwa kehadiran peran kegiatan keagamaan yang diikuti orangtua dalam partisipasi pengasuhan sangat memberikan manfaat bagi kelompok yang kurang beruntung misalnya perbedaan etinis dan ras yang minoritas.

$$
\text { Partisipasi aspek agama }
$$

memberikan dorongan kepada orang tua tunggal untuk bertindak lebih baik terhadap anak-anak mereka (Sullivian. S.C, 2008). Orangtua yang tidak mengalami permasalahan dan aktif dalam kegiatan keagamaan juga mempunyai pengaruh terhadap kesejahteraan kehidupan psikologis anak seperti tidak melakukan kekerasan terhadap anak-anak. Disisi lain kegiatan kerohanian mendorong orang tua untuk mengembangkan suasana keluarga yang berkualitas dalam kaitanya perilaku pengasuhan.

Berkembangnya ilmu pengetahuan semakin berkembang pula kehidupan para kaum perempuan untuk menyamakan derajatnya seperti kaum laki-laki dalam dunia karir seperti politik, hukum, maupun perekonomian. Tidak jarang lagi bagi kaum perempuan yang mengesampingkan kodratinya sebagai seorang ibu lebih memfokuskan terhadap pekerjaan dan karirnya demi mendapatkan pengakuan ataupun karena permasalahan perekonomian keuarga. Karir tersebut memicu para kaum perempuan memilih untuk menitipkan anaknya ke sekolah formal maupun non formal dengan alasan agar tetap dapat menjalankan aktivitasnya tanpa adanya kekhawatiran tarhadap kondisi anak ketika ditinggal bekerja. Akibat kesibukan orangtua, tidak sedikit peran agama dalam keluarga mengalami penurunan (Mahoney, 2010).

Akibat penurunan kualitas peran agama dalam keluarga tidak sedikit anak usia dini yang mengalami permasalahan. Seperti yang disampaikan (Setiawati \& Yogyakarta, 2006) fenomena perilaku negatif sudah mulai terjadi dalam kehidupan keseharian anak usia dini, seperti berbicara yang kurang sopan, menirukan perilaku orang dewasa, menirukan adegan kekerasan, dan sebagainya. Kondisi yang seperti itu memprihatinkan karena seharusnya usia anak-anak adalah usia dengan penuh kegembiraan dan pengembangan potensi diri namun yang terjadi justru sebaliknya.

Penyebab daripada perilaku anakanak yang menyimpang tadi salah satunya adalah kurangnya pendidikan dari orangtua atau orang dewasa di sekitarnya. Pada masa ini anak juga dalam masa meniru dan pembiasaan sehingga apabila lingkungan kurang mendukung akan menyebabkan munculnya perilaku yang kurang sesuai dengan moral agama pada tahapan seusianya.

Sesuai dengan tahap perkembangan moral menurut Kohlberg, anak usia 4-9 tahun berada pada taham prakonvensional yang mana tingkah laku anak dikendalikan oleh akibat fisik yang ditimbulkan melalui perbuatan yang biasa muncul dalam hadiah atau hukuman. Dengan demikian pembentukan pembiasaan perilaku moral dan nilai-nilai agama anak usia dini berdampingan dengan cara pembiasaan memberikan berbagai bentuk "iming-iming atau hadiah apabila anak melakukan sesuatu yang positif dan memberikan hukuman atau ancaman apabila anak melakukan perilaku yang kurang sesuai.

Dalam (Pendidikan \& Kebudayaan, 2014) disebutkan tingkat capaian perkembangan NAM anak 4-6 tahun adalah sebagai berikut:

Tabel 1. Standar Pencapaian Perkambangan Anak Usia Dini

\begin{tabular}{|l|l|}
\hline 4-5 Tahun doa & 5-6 Tahun \\
\hline $\begin{array}{l}\text { Mengucapkan jujur, } \\
\text { sebelum atau sesudah } \\
\text { melakukan sesuatu }\end{array}$ & $\begin{array}{l}\text { Berperilaku } \\
\text { penolong, sopan, } \\
\text { hormat, dan sportif }\end{array}$ \\
\hline $\begin{array}{l}\text { Mengenal perilaku } \\
\text { baik, sopan, dan buruk }\end{array}$ & Mengerjakan ibadah \\
\hline $\begin{array}{l}\text { Membiasakan diri } \\
\text { berperilaku baik }\end{array}$ & Menjaga lingkungan \\
\hline $\begin{array}{l}\text { Mengucap dan } \\
\text { membalas salam }\end{array}$ & $\begin{array}{l}\text { Menghormati } \\
\text { toleransi) } \\
\text { orang lain }\end{array}$ \\
\hline
\end{tabular}


176 | Participation of Mothers Who Work in Religious Activities Towards Child Behavior

Dari indikator Standar Tingkat Pencapaian Perkembangan Anak (STPPA) dijabarkan menjadi item dan butir menurt (Setiawati \& Yogyakarta, 2006) bahwa perilaku nilai agama moral pada anak usia 4-6 tahun diantaranya adalah mengucapkan doa-doa pendek, menyayangi dan memelihara semua ciptaan Tuhan, mulai menirukan gerakan-gerakan sholat yang dilaksanakan orang dewasa, berdoa sebelum dan sesudah memulai kegiatan, mencintai tanah air, mengenal musyawarah dan mufakat, cinta antara sesama suku bangsa Indonesia, mengenal sopan santun dengan berterima kasih, mengucap salam bila bertemu dengan orang lain, berlatih untuk selalu tertib dan patuh pada aturan, bertanggungjawab terhadap tugas yang diberikan.

Dalam penelitian ini akan dibahas bagaimana perilaku nilai agama moral anak usia 4-6 tahun dari latar belakang keluarga khususnya ibu yang bekerja dengan aktif mengikuti kegiatan keagamaan di tempat ibadah maupun kegiatan keagamaan yang diselenggarakan di sekolah. Sementara anak yang diteliti adalah anak yang mengikuti program pendidikan formal yakni taman kanak-kanak.

\section{METODOLOGI}

Penelitian ini mendeskripsikan perbandingan variabel perilaku nilai agama moral anak usia 4-6 tahun di TK ABA Babakan Kecamatan Srandakan, Bantul, Yogyakarta sebanyak 26 anak dari latar belakang ibu yang bekerja, 13 anak dari ibu yang mengikuti kegiatan keagamaan dan 13 anak dari ibu yang tidak mengikuti kegiatan keagamaan. Pengambilan data melalui observasi dan wawancara terhadap guru dan walimurid. Pedoman observasi berupa ceklis dilakukan peneliti dan guru di sekolah serta orang tua di rumah untuk melihat konsistensi perilaku anak antara di rumah dan di sekolah.

\section{HASIL DAN PEMBAHASAN}

Penelitian dilakukan pada bulan Agustus sampai Oktober 2018. Hasil skor yang diperoleh dari instrumen observasi ceklis pada anak dengan ibu yang mengikuti kegiatan keagamaan adalah sebagai berikut:

Tabel 2. Hasil analisis data perilaku anak dari ibu yang mengikuti kegiatan keagamaan.

\begin{tabular}{|l|l|l|}
\hline No & Uji & Nilai \\
\hline 1 & Rerata & 9 \\
\hline 2 & Nilai Minimal & 81.25 \\
\hline 3 & Nilai Maksimal & 100 \\
\hline 4 & SD & 7 \\
\hline & & \\
\hline
\end{tabular}

Dari hasil analisis Tabel 2 perilaku nilai agama moral anak dari ibu yang mengikuti kegiatan keagamaan dikategorisasikan dalam bentuk grafik sebagai berikut:

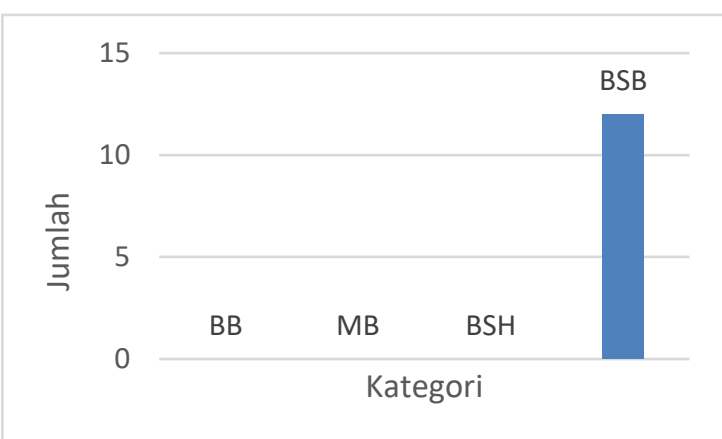

Grafik 1. Hasil Skor Perilaku NAM anak dari ibu yang mengikuti kegiatan keagamaan

Selanjutnya adalah hasil skor yang diperoleh dari instrumen observasi ceklis pada anak dengan ibu yang tidak mengikuti kegiatan keagamaan adalah sebagai berikut:

Tabel 3. Hasil analisis data perilaku anak dari ibu yang tidak mengikuti kegiatan keagamaan

\begin{tabular}{|l|l|l|}
\hline No & Uji & Nilai \\
\hline 1 & Rerata & 5 \\
\hline 2 & Nilai Minimal & 44 \\
\hline 3 & Nilai Maksimal & 63 \\
\hline 4 & SD & 6.4 \\
\hline
\end{tabular}

Dari hasil analisis Tabel 3 perilaku nilai agama moral anak dari ibu yang tidak mengikuti kegiatan keagamaan akan diketegorisasikan dalam bentuk grafik sebagai berikut: 


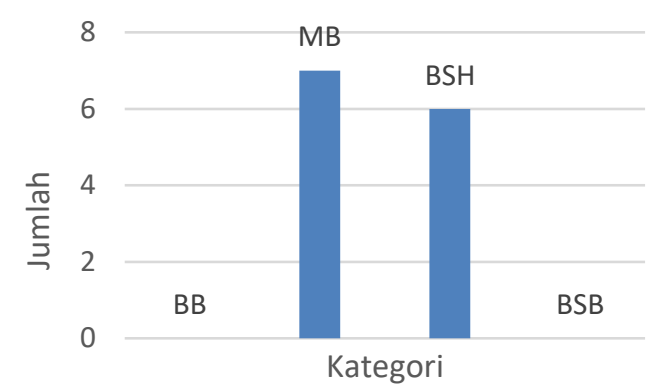

Grafik 2. Hasil Skor Perilaku NAM anak dari ibu yang tidak mengikuti kegiatan keagamaan.

Hasil uji normalitas dengan rumus Kolmogorov Smirnov diperoleh signifikansi dari kedua kelas sebesar 0.48 dan 0.18 atau keduanya < probabilitas yakni 0.05 sehingga data dikatakan tidak normal. Uji homogenitas diperoleh hasil signifikansi sebesar 0.905 atau > probabilitas yakni 0.05 sehingga data dikatakan homogen. Uji hipotesis menggunakan uji t man whitney karena data homogen namun tidak berdistribusi normal. Hipotesis dalam penelitian ini adalah $\mathrm{Ha}=$ ada perbedaan perilaku nilai aga moral anak dari ibu yang mengikuti kegiatan keagamaan maupun tidak. Diperoleh hasil signifikansi atau asymp. Sig (2-tailed) 0.00 atau lebih kecil dari probabilitas yakni 0.05, sehingga $\mathrm{Ha}$ diterima atau terdapat perbedaan perilaku agama moral anak antara ibu yang mengikuti partisipasi kegiatan keagamaan dan ibu yang tidak mengikuti partisipasi kegaiatan keagamaan.

\section{PEMBAHASAN}

Setiap anak yang terlahir sudah memiliki potensi dalam diri. Potensi yang dimiliki anak usia dini penting untuk dikembangkan karena pada masa tersebut anak sedang berada dalam tahap perkembangan dan pertumbuhan disemua aspek yang nantinya aspek tersebut bermanfaat untuk kebutuhan hidup dimasa selanjutnya (Suyadi, 2010). Salah satu potensi dalam diri anak adalah aspek keagamaan (M. Pendidikan, Kebudayaan, \& Indonesia, 2014). Dalam aspek keagamaan terdapat dua unsur yakni aktivitas keagamaan dan perilaku nilai agama moral(Fauzia, 2015). Penelitian ini akan di khususkan pada perilaku nilai agama moral anak dari latar belakang orangtua/ibu yang bekerja.

Pentingnya untuk mengembangakan aspek perilaku nilai agama moral anak karena perilaku tersebut akan terus berlanjut selama hidupnya nanti. Anak berada dalam masa emas atau golden age dan pembentukan fondasi awal bagi individu alangkah baiknya jika orang dan lingkungan sekitar memberikan stimulasi yang tepat dalam kesempatan ini (Setiawati \& Yogyakarta, 2006).

Secara umum pendidikan perilaku moral penting distimulasikan untuk anak karena pendidikan moral akan mengarahkan manusia agar bertindak sesuai dengan budi pekerti, berakhlak, dan beretika. Selain itu, harapan dari pendidikan moral agar nantinya anak mampu menggunakan pengetahuan, mengembangkan ketrampilan sosial, mengkaji dan menginternalisasi nilai yang memungkinkan untuk tumbuh dan berkembangnya akhlak mulia serta mampu mewujudkanya dalam perilaku keseharian diberbagai kehidupan sosial budaya selama sepanjang hayat (Zuriah, 2008). Lebih lanjut lagi tujuan dari aspek pendidikan agama adalah meningkatkan keimanan, pemahaman, penghayatan, dan pengalaman peserta didik tentang agama islam sehingga nantinya menjadi individu yang bertakwa pada Allah SWT, berakhlak mulia dalam kehidupan pribadi, masyarakat, berbangsa, dan bernegara serta dapat melanjutkan pada jenjang pendidikan yang lebih tinggi (Majid, Abdul dan Andayana, 2010).

Perilaku nilai agama moral pada anak usia 4-6 tahun yang perlu diperhatikan stimulasinya antara lain membiasakan berdoa sebelum dan sesudah melakukan kegiatan, menyayangi dan memelihara semua ciptaan Tuhan, mengenal musyawarah dan mufakat, cinta antara sesama suku bangsa Indonesia, mengenal sopan santun dengan berterima kasih, mengalah, tidak mudah marah, minta maaf apabila melakukan kesalahan, mengucap salam bila bertemu dengan orang lain, berlatih untuk selalau tertib dan patuh pada aturan, menjaga kebersihan lingkungan, 
bertanggungjawab terhadap tugas yang diberikan.

Perilaku nilai agama moral dapat diterima oleh anak melalui imitasi keteladanan dari lingkungan orang sekitar (Choiriyah, 2009). Keteladanan merupakan cara belajar dengan cara meniru perilaku maupun sikap tokoh seseorang (Arief, 2002). Di dalam lingkungan keluarga tokoh yang akan menjadi teladan adalah orang yang lebih tua.

Selain dengan imitasi keteladanan perilaku, penanaman perilaku nilai agama moral akan terbentuk dengan pembiasaan (Khadijah, 2016). Yang dimaksud dengan pembiasaan adalah sebuah cara yang dapat dilakukan untuk membiasakan anak didik berfikir, bersikap, dan bertindak sesuai dengan tuntutan agama islam (Arief, 2002). Pembiasaan yang akan diterima anak adalah lingkungan kehidupan dimana anak tinggal. Penanaman perilaku keagamaan melalui pembiasaan perilaku dalam proses pembelajaran akan berbeda dengan penanaman ilmu pengetahuan yang dapat diperoleh dengan belajar. Sifat sopan santun dan akhlak akan lebih mudah diterima oleh anak melalui pembiasaan (Richard, 2012). Pembiasaan anak merupakan pembiasaan orang tua, orang tua yang terbiasa berperilaku baik maka perilaku anakpun akan baik, begitu juga sebaliknya apabila orangtua tidak berperilaku baik maka perilaku anak juga tidak jauh berbeda dengan orangtua.

Peran utama pengasuhan dalam keluarga adalah ibu. Namun bagi seorang ibu yang mempunyai pekerjaan merupakan tantangan tersendiri dalam hal pengasuhan untuk anak-anaknya. Seorang ibu yang berpredikat bekerja memiliki intensitas waktu dengan anak lebih sedikit dari pada ibu yang tidak bekerja. Berdasarkan temuan peneliti melalui observasi dan wawancara terhadap orang tua, alternatif yang dilakukan agar tetap memberikan perhatian pada anak-anaknya adalah mengantarkan anak berangkat sekolah walaupun saat pulang sekolah anak dijemput oleh nenek maupun pengasuh. Perhatian selebihnya diberikan setelah ibu pulang dari bekerjanya. Karena waktu yang dimiliki orangtua untuk anak-anaknya tidak banyak, sangat diperlukan bagi orangtua untuk memperoleh sumber pengetahuan tentang bagaimana cara mendidik dan berperilaku. Salah satu kegiatan yang dapat mendukung dan memberikan arahan orang tua dalam berperilaku maupun bersikap di depan anak adalah dengan mengikuti kegiatan keagamaan (Petts, 2012). Beberapa kegiatan diantaranya adalah parenting yang diselenggarakan di sekolah anak. Dalam kegiatan parenting orangtua akan diberikan arahan bagaimana memberikan stimulasi di rumah yang sesuai dengan tahapan perkembangan anak. Selain diberikan arahan dalam memberikan stimulasi, orangtua juga dibekali siraman rohani oleh tokoh agama mengenai bagaimana adab dan tata cara orang tua dalam mandidik anak karena status anak adalah titipan dari Tuhan. Program tersebut berlangsung di TK ABA Babakan Bantul karena latar belakang sekolah tersebut berada dalam satu naungan yayasan dengan lembaga keagamaan daerah setempat. Selain mengikuti kegaitan yang diselenggarakan di sekolah, ada beberapa orangtua yang juga mengikuti kajian di tempat ibadah saat akhir pekan seperti kajian minggu pagi yang diselenggarakan pada komunitas setempat.

Mengikuti partisispasi kegiatan keagamaan baik yang diselenggarakan di sekolah maupun di lembaga keagamaan, orang tua mendapatkan bekal bagaimana harus berperilaku di depan anak sebagai stimulasi perkembangan. Orang tua mendapatkan pengarahan dan ilmu bagaimana untuk mendidik dan bersikap di depan anak mereka. Salah satu stimulasi dari orang tua yang dapat dilakukan secara tidak langsung adalah perilaku yang berkaitan dengan pembiasaan di rumah.

Perilaku pembiasaan keseharian orangtua misalnya pembiasaan bertingkahlaku kaitanya dengan ritualisme seperti berdoa sebelum dan sesudah melakukan kegiatan (makan\&minum, tidur, masuk toilet, bercermin,dll), bertuturkata sopan dan santun, membiasakan mengucapkan terimakasih, minta maaf apabila melakukan salah, menghargai aturan di dalam rumah yang telah disepakati 
bersama, saling menyayangi anggota keluarga, menirukan gerakan sholat yang dilakukan orang tua atau ibadah sejenisnya.

Hasil penelitian yang dilakukan melalui observasi kurang lebih selama dua bulan terdapat perbedaan perilaku antara anak dari ibu yang mengikuti kegiatan keagamaan dan ibu yang tidak mengikuti kegiatan keagamaan. Perbandingan ini dapat dilihat dari hasil uji t Mann Whitney yakni hasil signifikansi atau asymp. Sig (2tailed) sebesar 0.00 atau lebih kecil dari probabilitas yakni 0.05 , sehingga $\mathrm{Ha}$ diterima atau dengan kata lain terdapat perbedaan perilaku diantara anak dari ibu yang mengikuti kegaiatan keagamaan dan yang tidak mengikut kegiatan keagamaan.

\section{SIMPULAN}

Lingkungan merupakan salah satu objek penanaman perilaku nilai agama moral untuk anak usia dini. Penanaman perilaku tersebut dapat distimulasi dengan metode pembiasaan dan keteladanan dari orang-orang sekitar seperti keluarga. Peran keluarga yang dominan memberikan pengaruh terhadap perilaku anak adalah ibu. Namun akan berbeda permasalahanya ketika seorang ibu memiliki pekerjaan. Ibu yang memiliki pekerjaana akan memiliki intensitas waktu untuk anak lebih sedikit daripada ibu yag tidak bekerja. Sementara bekal ilmu orangtua untuk menjadi contoh atau mendidik anak salah satunya adalah kegiatan keagamaan, karena dalam kegiatan tersebut orang tua akan dibekali ilmu tentang bagaiman acara mendidik anak. Orangtua dapat mengikuti kegiatan keagmaan yang diselenggarakan di sekolah anak atau sering disebut parenting dan kegiatan keagamaan yang diselenggarakan di tempat ibadah setempat. Berdasarkan penelitian yang dilakukan terhadap subjek dari orang tua yang memiliki pekerjaan dengan 13 anak dari ibu yang mengikti kegiatan keagamaan dan 13 anak dari ibu yang tidak mengikuti kegiatan keagamaan. Hasil menunjukan terdapat perbedaan perilaku dari kedua jenis subjek tersebut. Perilaku anak dari ibu yang mengikuti kegiatan keagamaan cenderung tidak tempramen, mampu menahan emosi, saling membantu, mudah memaafkan serta terbiasa berdoa sebelum dan sesudah melakukan kegiatan. Temuan ini membuktikan bahwa pengasuhan peran ibu di lingkungan rumah sangat berpengaruh walaupun sibuk dengan pekerjaanya.

\section{UCAPAN TERIMA KASIH}

Terimakasih saya ucapkan kepada Tuhan YME yang telah memberikan kesempatan dan kelancaran dalam penelitian dan pembuatan jurnal ini. Terima kasih kepada pihak yang telah memberikan dukungan dalam penelitian dan pembuatan jurnal ini.

\section{DAFTAR PUSTAKA}

Arief, A. (2002). Pengantar ilmu dan metodologi pendidikan islam. Jakarta: Ciputra pers.

Bakry, O. (1993). Ahlak muslim. Jakarta: Raja Grafindo Persada.

Choiriyah, A. (2009). Pengembangan keagamaan pada anak usia dini. Fakultas Tarbiyah UIN Sunan Kalijaga.

Fauzia, S. N. (2015). Perilaku keagamaan islam pada anak usia dini. Jurnal Pendidikan Anak Usia Dini, 9(2).

Hurlock, E. B. (1978). Perkembangan anak. Jakarta: Erlangga.

Isticharoh. (2007). Penerapan metode pembiasaan dalam pembentukan ahlak pada anak prasekolah di TKIT Permata Hati Ngaliyan Semarang. Semarang. IAIN Sunan Walisongo.

Jailani, O. M. S. (2014). Teori pendidikan keluarga dan tanggungjawab orangtua dalam pendidikan anak usia dini, 90-102.

Khadijah. (2016). Pengembangan kognitif anak usia dini 1. Raudhah, 4(1).

Langgulung, H. (1986). Manusia dan Pendidikan. Jakarta: AI-Husna.

Mahoney, A. (2010). A relational spirituality framework. Journal of Marria and Family, 72.4, 805-827.

Majid, Abdul dan Andayana, D. (2010). Perkembanga pembelajaran anak usia dini, (73111331), 10-42. 
180 | Participation of Mothers Who Work in Religious Activities Towards Child Behavior

Pendidikan, K., \& Kebudayaan, D. A. N. (2015). Peraturan mentri pendidikan dan kebudayaan republik indonesia.

Pendidikan, M., Kebudayaan, D. A. N., \& Indonesia, R. (2014). Perauran mentri pendidikan dan kebudayaan republik indonesia.

Petts, R. J. (2012). Single mothers' religious participation and early childhood behavior. Journal of Marriage and Family, 74(2)(251-268).

Richard, J. (2012). Single Mothers â $€^{\mathrm{TM}}$ Religious Participation and Early Childhood Behavior.

Setiawati, F. A., \& Yogyakarta, U. N. (2006). Pendidikan moral dan nilainilai agama pada anak usia dini: bukan sekedar rutinitas, (2).

Sullivian. S.C. (2008). Unaccompained Children in Churches: low income urban single mother religion and parentin. Review of Religious Research, 50, 157-1875.

Suyadi. (2010). Psikologi Belajar PAUD Pendidikan Anak Usia dini. Yogyakarta: Pedagogia.

Suyanto, S. (2005). Konsep dasar perkembangan anak. Jakarta: Departemen Pendidikan Nasional Direktorat Jenderal Pendidikan Tinggi.

Zhai, Jiexia Elisa, Ellison G. Christopher, dan Glenn, N. D. (2007). Parental Divorce and Religious Involvement among Young Adult. Journal of Sociology Religion, 68(2).

Zuriah, N. (2008). Pendidikan moral dan budi pekerti dalam perspektof perubahan. Jakarta: Bumi Aksara. 